\title{
Icing Analysis of Kleče-Logatec Transmission Line with Two-Level Icing Model
}

\author{
Dávid Szabó $^{1(\bowtie)}$, Bálint Németh ${ }^{1}$, Gábor Göcsei ${ }^{1}$, Viktor Lovrenčić ${ }^{2}$, \\ Nenad Gubeljak ${ }^{3}$, Uršula Krisper ${ }^{4}$, and Matej Kovač ${ }^{5}$ \\ ${ }^{1}$ Budapest University of Technology and Economics, Budapest, Hungary \\ szabo.david@vet.bme.hu \\ ${ }^{2}$ C\&G d.o.o., Ljubljana, Slovenia \\ ${ }^{3}$ Faculty of Mechanical Engineering, University of Maribor, Maribor, Slovenia \\ ${ }^{4}$ Elektro Ljubljana d.d., Ljubljana, Slovenia \\ 5 OTLM d.o.o., Ljubljana, Slovenia
}

\begin{abstract}
FLEXITRANTORE as a HORIZON 2020 project aims to develop an integrated platform for the next generation flexible electricity transmission system. During the project the investigation and implementation of state-of-theart technologies will be realized, like storage systems, new market designs and business models, Dynamic Line Rating (DLR) technology or de-icing methodologies. The objective of FLEXITRANTORE's WP7 work package is to develop a DLR based anti-icing technology for transmission lines, therefore make the grid more reliable [1].

The aim of this paper is to present the investigation of complex icing system for transmission grid. The introduced investigation forms a two-level method, which in the first stage gives a warning for system operators, when the environmental factors are appropriate for ice formation on conductors. Then a mathematical model forecasts the radius and mass of the expected ice-layer. The second level of the system monitoring the ice-formation on the phase conductors with line-monitoring sensors, thus the system operators get real information about the line condition. The operation of the methodology is also investigated, which are also presented through case studies.
\end{abstract}

Keywords: Flexitranstore $\cdot$ Overhead line $\cdot$ DLR $\cdot$ Ice prediction $\cdot$ Ice detection

\section{Introduction}

An Integrated Platform for Increased FLEXIbility in smart TRANSmission grids with STORage Entities and large penetration of Renewable Energy Sources (hereinafter referred to as FLEXITRANSTORE) is a project supported by the European Union's Horizon 2020 research and innovation programme. The main purpose of FLEXITRANSTORE is to improve the pan European transmission network to a high level of flexibility with high interconnection levels [1]. 
The aim of FLEXITRANSTORE's Work Package 7 is to develop a de-icing method for transmission lines based on Dynamic Line Rating (DLR) calculation process. DLR is a weather-based calculation methodology for uprating transmission capacity of existing power lines, thereby which can be used as lines with high temperature conductors. DLR offers temperature tracking calculation of the wires for the safety operation during extreme conditions, which can be reached as the result of prediction of local thermal overloads. On the other hand, ice layer can be formatted on the conductors in the winter extraordinary weather conditions, which should be also handled. A complex ice prediction model under development on the basis of DLR's environmental monitoring function. In the first stage, one of the demonstration lines was investigated based on the collected field data, which gives the principle of the method $[2,3]$.

\section{BME's Ice Prediction Model}

Besides the geometry of the conductor, local environmental conditions, such as rainfall, ambient temperature, humidity, wind speed and direction, also play an important role in the formation of ice layer on the surface of the conductors. These parameters determine the structural properties of the resulting ice layer and thus its properties. Based on these environmental factors, three types of ice can be distinguished, which can cause high mechanical extra load to the conductors through high-adhesion and density. These three ice types are wet snow, glaze and hard rime.

BME's ice type determining system is established to predict the expected ice type based on environmental parameters, on which based the ice layer diameter and extent of extra mechanical load can be calculated according to the actual ice type. The algorithm takes into account the ambient temperature, precipitation type and intensity, relative humidity and also the temperature of the conductors in order to determine the expected ice type. The results of the system can be the following: wet snow, mixture of wet snow and glaze, glaze, mixture of glaze and hard rime, hard rime or ice formation is not expected. Ice can only shape when conductor temperature below $2{ }^{\circ} \mathrm{C}$, but due to the uncertainty of the conductor temperature calculation model and the deviation of line monitoring devices, this threshold value was set to $3{ }^{\circ} \mathrm{C}$ in the model, which appears as a safety factor while it can be also increase the number of false alarms [4].

The structure of the ice layer deposited on the overhead line conductors largely depends on the type of precipitation, which through several parameters - water droplet/snowflake velocity and mass concentration, collision efficiency, adhesion factor, deposition factor - influences the forming ice layer. In this way, the ice layer will be accreted differently for different types of ice, so the calculation of the thickness of the resulting ice sleeve and the consideration of the extra mechanical load caused by it should be calculated in different ways depending on the type of ice. BME's ice determining system use Lacavalla et al. model [5, 6] for wet snow calculation, Pytlak et al. model [7] for glaze computation and Shao et al. model [8] for hard rime estimation. 


\section{Ice Detection System of OTLM}

\subsection{Development of OTLM Line Monitoring Sensor}

Severe ice storm was observed in Slovenia in 2014, which indicates the demand for new safety measures during overhead lines operations. For this purpose, one of the additional safety precautions was to inspect the overhead lines when received information from national weather service that ice storm is possible in the given region. Based on this forecast information the TSO should check if ice storm is affected the overhead line or not. Unfortunately, some overhead lines are located high in the hills and approach is nearly impossible in case of snowy winter time. These facts encourage the manufacturer to build a camera into OTLM line monitoring sensor, which can be used for monitoring overhead lines and to check the ice status on overhead line conductors.

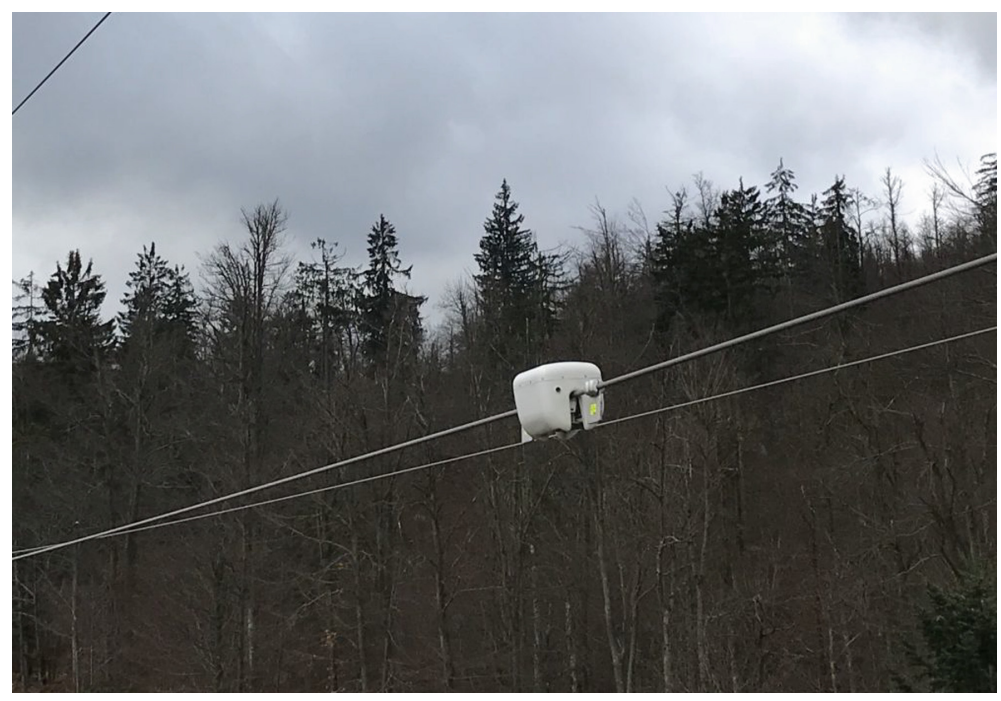

Fig. 1. OTLM line monitoring sensor

Beside the presence of the ice, operator can check what kind of ice is present - glaze ice, wet snow, etc. In case of icing event system operator is able to heat the conductor, then the critical point will be the tower. Thus, OTLM's camera was turned towards the tower to check the conductor and the tower at once. This feature enables the operator to check the status of overhead lines in real-time without the presence of maintenance personnel and act accordingly on the real status. 


\subsection{OTLM's Ice Detection Function}

This chapter presents the concept of the application and the relation between the geometry and load parameters on the catenary curve when ice or heavy snow builds up.

Mathematical model has been developed for sag and horizontal force calculation. The model includes installation conditions and conductor characteristics and determines the interdependence between conductor sag and horizontal force for actual conductor temperatures based on mechanical and physical characteristics of the conductor, conductor weight and sag size. Combining measurements of conductor geometry and sag at several conductor temperatures with software are used for calibration of the sag and angle function. Ensuring conformity is crucial for the implementation of the ICEALARM function, since a continued growth of discrepancy between the measured and calculated angle in ambient conditions is a sign of glaze ice on the conductor.

The parameters of the catenary curve at the temperature of the freezing rain represent the initial state of the activation of the ICE-ALARM computer algorithm. If favorable conditions for the formation of ice appear during the continuous monitoring of the conductor condition and condition on the route in the surroundings of the meteorological station, then it is possible to estimate the amount of additional loading and the ice thickness on the basis of the change in the angle of inclination and by knowing the tension-deformation behavior of the conductor at increased loading.

Figure 2 shows the change in the angle in accordance with the model and the angle measured by the inclinometer. White circles present actual average angles as a function of average temperature of conductor measured in the time interval of $30 \mathrm{~s}$. Red circles presents the expected behavior of the conductor and/or a change in the angle due to the

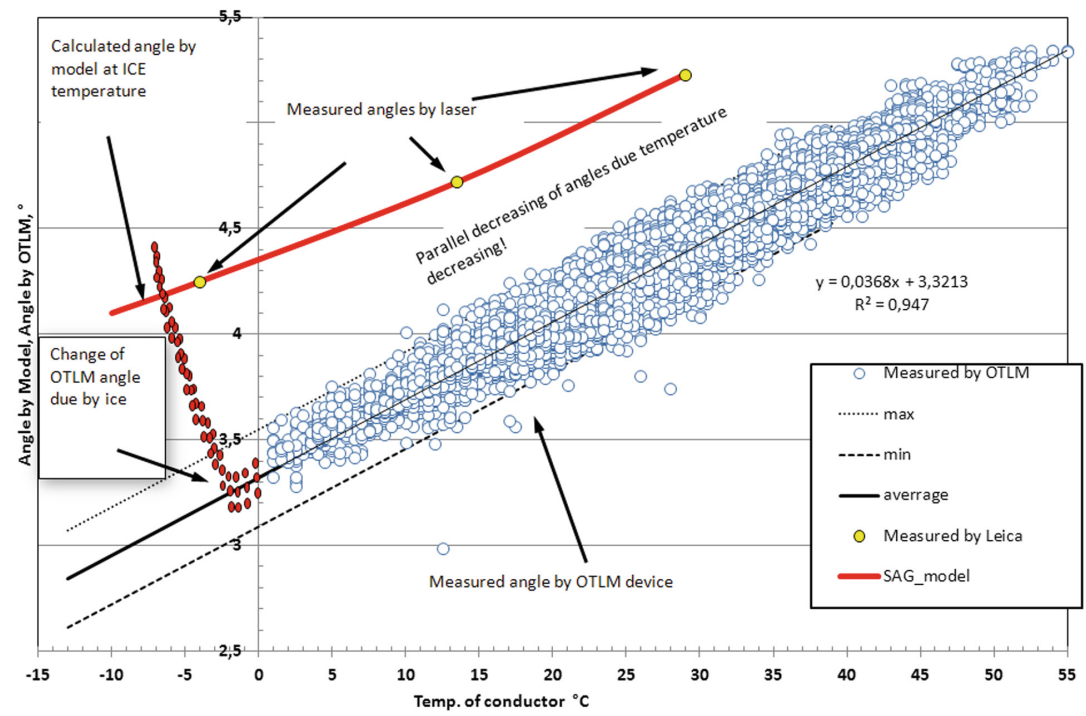

Fig. 2. Change in an angle at the OTLM device position depending on temperature 
build-up of the ice on the conductor. The continuous red line represents the angle of inclination depending on temperature according to the mathematical model. If an angle significantly increases in the meteorologically favorable ice conditions and the temperature inversion and if the calculated angle significantly differs from the angle measured by inclinometer, the application informs the operator that ice has built up on the conductor [9-11].

\section{Two-Level Icing Model}

Based on BME's ice prediction model and OTLM's ice detection function a two-level model was established and under implementation for Kleče -Logatec transmission line. In this way the ice accretion can be predicted based on weather forecast according to BME's ice type determining system co-operated with national weather service (ARSO). The accreting ice layer can pose a threat if the sleeve radius exceeds $10 \mathrm{~mm}$ or if the extra mechanical load caused by it exceeds $1 \mathrm{~kg} / \mathrm{m}$ during the icing event. Therefore, the threshold values for ice alarm settled to be according to these limitations.

Furthermore, if ice alarm was sent to the system operators, they can monitor the real field conditions of the conductors with OTLM device, which can not only measure the inclination of the monitored span, but also the conductors state can be observed with the built-in camera. Therefore, the ice prediction model's results can be compared with the actual conditions, and the required intervention can be determined according to the growth rate of the ice layer.

\section{Case Studies}

To illustrate the operation of the two-level icing model, some case studies are presented here. Although, there was a "green winter", which means there was no considerable icing, only some snowing events occurred, nevertheless the operation of the model can be showed through these snowing events. Case studies was made for Kleče-Logatec $110 \mathrm{kV}$ single circuit transmission line equipped with $240 / 40 \mathrm{~mm}^{2}$ ACSR conductors.

\subsection{November 2018}

BME's model predicted wet snow and glaze ice types based on weather forecast for different grid points. The expected ice thickness was 5 to $6 \mathrm{~mm}$ for glaze and 10 to $14 \mathrm{~mm}$ for wet snow. Figure 3 shows the accretion of glaze ice depending on precipitation intensity. 


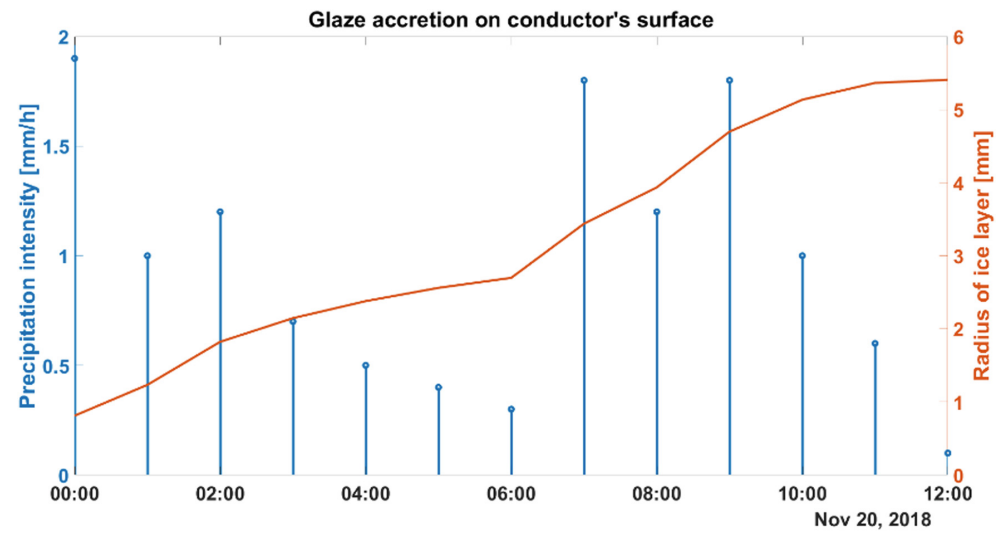

Fig. 3. Glaze accretion according BME's model - 20 November 2018

On the other hand, as Fig. 4 shows the image captured by OTLM device, there is a slight ice layer can be seen on the bottom of the wire.

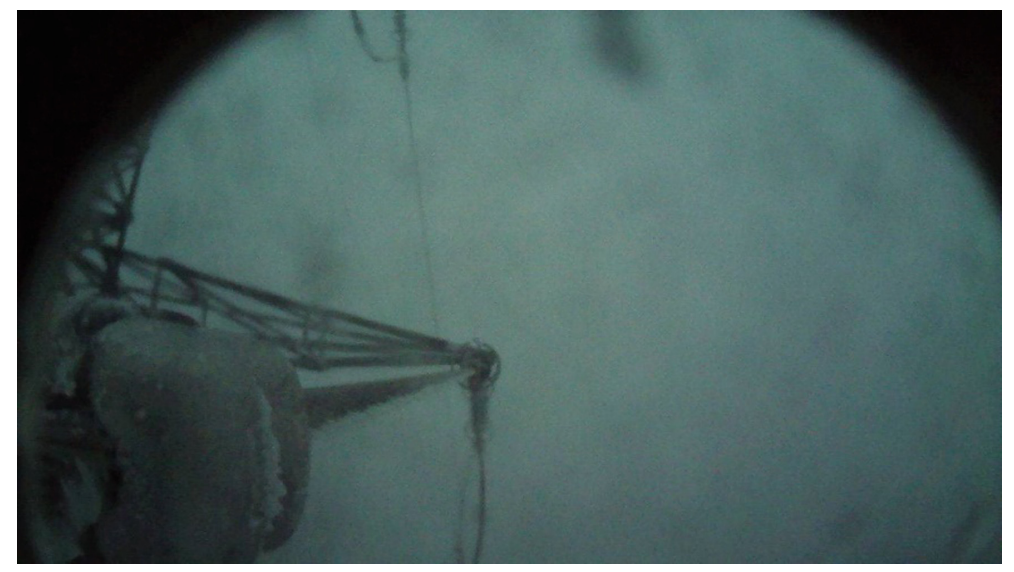

Fig. 4. Real state of a phase conductor - 20 November 2018

\subsection{January 2019}

A mixed type of ice from wet snow and glaze was anticipated according to BME's ice prediction model with a thickness between 9 to $12 \mathrm{~mm}$ for the different forecast grid points. The expected ice formation is shown in Fig. 5. 


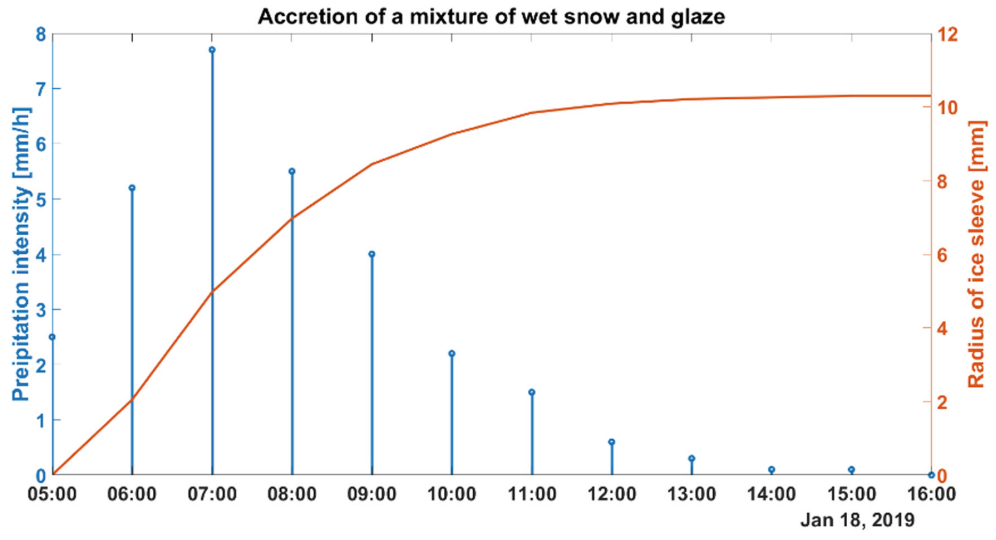

Fig. 5. Glaze accretion according BME's model - 18 January 2019

The real field conditions are shown in Fig. 6, where a huge snow deposit can be seen front of the camera, and a layer of ice on the tower.

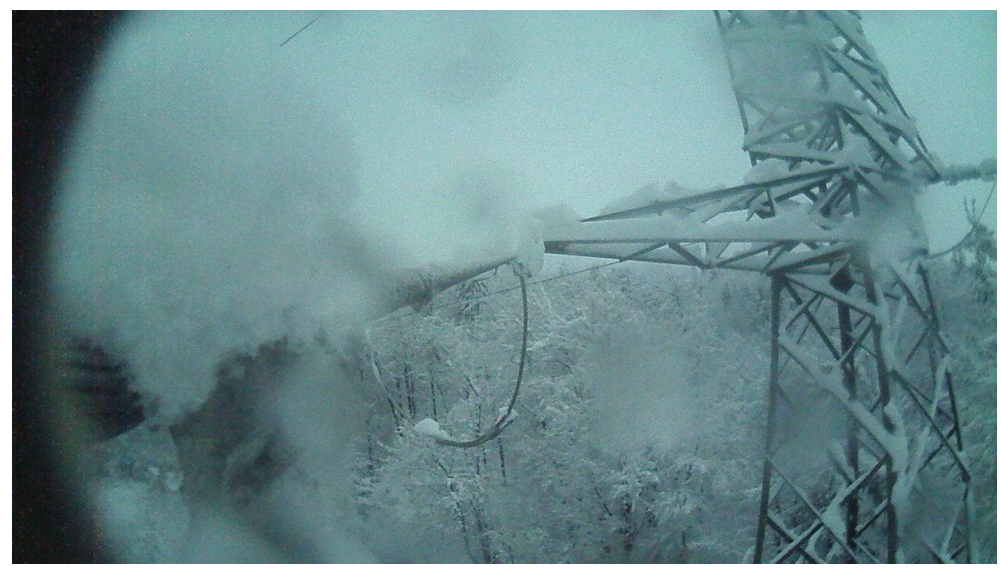

Fig. 6. Real state of a phase conductor - 18 January 2019

\subsection{Summary of Case Studies}

The operation of the model was investigated in 2018-19 winter time, when only slight ice formed on the conductors mostly form wet snow. BME's ice prediction model forecasted properly the ice formation, while the quantitative estimation should be finetuned, when significant ice sleeves will occur. On the other hand, OTLM device offers an appropriate solution for real-time monitoring of the conductors, which can be the basis to the intervention for system operators. 


\section{Conclusion}

According to FLEXITRANSTORE's project this paper presented the development of a two-level ice prediction and detection model for high voltage overhead lines. The first level is a weather-based system, which aims to predict the possibility of different ice types - wet snow, glaze, hard rime - accretion on conductors. The model is able to calculate the radius of the ice sleeve and its mechanical extra load based on the accreting ice layer's type. On the second level a computer algorithm was developed for re-calculation of the sag and tensile strains in the conductor. It takes into account the actually measured form of the catenary curve of the conductor on the presented span at the conductor temperature measured by OTLM. Based on the knowledge about the change in the sag of the catenary curve and the tensile forces dependence on the temperature of the conductor and monitored weather conditions, it is possible to determine the moment of activation the ICE-ALARM application. Furthermore, OTLM sensor is able to monitor the actual state of the conductors with its camera.

The essence of the two-level system is the prediction opportunity combined with the real-time monitoring function. System operators get a forecast of the seriousness of the icing event in this way, while the intervention can be made according to the danger factor, therefore the number of unnecessary interventions can be reduced.

Acknowledgements. This work has been developed in the High Voltage Laboratory of Budapest University of Technology and Economics within the boundaries of FLEXITRANSTORE project, which is an international project. FLEXITRANSTORE (An Integrated Platform for Increased FLEXIbility in smart TRANSmission grids with STORage Entities and large penetration of Renewable Energy Sources) aims to contribute to the evolution towards a panEuropean transmission network with high flexibility and high interconnection levels.
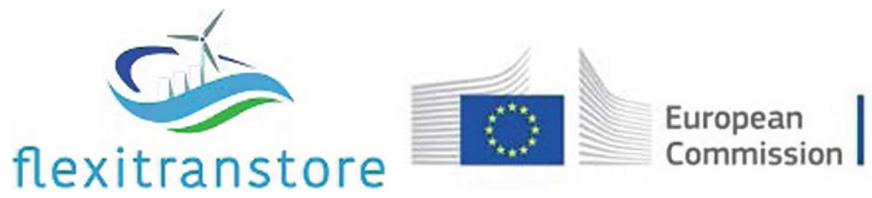

Horizon 2020

European Union funding

for Research \& Innovation

\section{References}

1. FLEXITRANSTORE: European Union's Horizon 2020 Project. http://www.flexitranstore.eu/

2. Rácz, L., Szabó, D., Göcsei, G., Németh, B.: Grid management technology for the integration of renewable energy sources into the transmission system. In: 2018 7th International Conference on Renewable Energy Research and Applications (ICRERA), Paris, 2018, pp. 612-617 (2018)

3. Halász, B.G., Németh, B., Rácz, L., Szabó, D., Göcsei, G.: Monitoring of actual thermal condition of high voltage overhead lines. In: Camarinha-Matos, L., Adu-Kankam, K., Julashokri, M. (eds.) Technological Innovation for Resilient Systems. DoCEIS 2018. IFIP Advances in Information and Communication Technology, vol. 521. Springer, Cham (2018) 
4. Szabó, D.: Development of dynamic line rating system. MSc thesis, Budapest University of Technology and Economics, Budapest (2019)

5. Lacavalla, M., Marcacci, P., Frigerio, A.: Forecasting and monitoring wet-snow sleeve on overhead power lines in Italy, pp. 78-83 (2015). https://doi.org/10.1109/eesms.2015. 7175856

6. Lacavalla, M., Bonelli, P., Mariani, G., Marcacci, P., Stella, G.: The WOLF system: forecasting wet-snow loads on power lines in Italy. In: 14th International Workshop on Atmospheric Icing of Structure, 8-13 May 2011, Chongqing (2011)

7. Pytlak, P., Musilek, P., Lozowski, E., Arnold, D.: Evolutionary optimization of an ice accretion forecasting system. Mon. Weather Rev. 138(7), 2913 (2010)

8. Shao, J., Laux, S.J., Trainor, B.J., Pettifer, R.E.W.: Nowcasts of temperature and ice on overhead railway transmission wires. Meteorol. Appl. 10, 123-133 (2003). https://doi.org/ $10.1017 / \mathrm{s} 1350482703002044$

9. Lovrenčič, V., Gubeljak, N., Banić, B., Ivec, A., Kozjek, D., Jarc, M.: On-line monitoring for direct determination of horizontal forces vs. temperature and incline angle of transmission conductor. In: Fourth Session of Cired Croatian National Committee), 11th Symposium on power system management HRO-CIGRE, Opatija, Croatia, November 2014

10. Lovrenčič, V., Gabrovšek, M., Kovač, M., Gubeljak, N., Šojat, Z., Klobas, Z.: The contribution of conductor temperature and sag monitoring to increased ampacities of overhead lines (OHLs). In: DEMSEE 2015 10th International Conference on Deregulated Electricity Market Issues in South Eastern Europe, Budapest, Hungary, September 2015

11. Gubeljak, N., Lovrenčić, V., Banić, B., Pinterič, M., Jarc, M.: Application of an ice-alarm in the OTLM system. In: First South-East European CIGRE Conference, Portorož (2016)

Open Access This chapter is licensed under the terms of the Creative Commons Attribution 4.0 International License (http://creativecommons.org/licenses/by/4.0/), which permits use, sharing, adaptation, distribution and reproduction in any medium or format, as long as you give appropriate credit to the original author(s) and the source, provide a link to the Creative Commons license and indicate if changes were made.

The images or other third party material in this chapter are included in the chapter's Creative Commons license, unless indicated otherwise in a credit line to the material. If material is not included in the chapter's Creative Commons license and your intended use is not permitted by statutory regulation or exceeds the permitted use, you will need to obtain permission directly from the copyright holder.

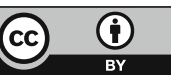

